\title{
Financial Decision Making and Cognition in a Family Context
}

\author{
James P. Smith ${ }^{\mathrm{a}}$, John J. McArdle ${ }^{\mathrm{b}}$, and Robert Willis ${ }^{\mathrm{c}}$ \\ ${ }^{a}$ Chair, Labor Markets and Demographic Studies, RAND Corporation \\ bSenior Professor of Psychology, University of Southern California \\ 'Professor of Economics, University of Michigan
}

\begin{abstract}
In this paper, we studied the association of cognitive traits and in particular numeracy of both spouses on financial outcomes of the family. We found significant effects, particularly for numeracy for financial and non-financial respondents alike, but much larger effects for the financial decision maker in the family. We also examined who makes these financial decisions in the family and why. Once again, cognitive traits such as numeracy were an important component of that decision with larger effects of numeracy for husbands compared to wives.
\end{abstract}

Individuals prefer not to live alone with the family being the most basic and important social unit that combines us into groups. Specialization of functions within the family is well established by economists with the most prominent example being work in the labor market and work in the home (Becker, 1991). But many other dimensions of economic related decisions are made within the family for the common good, including the rearing and training of children, the composition and purchase of consumption, and the accumulation of family wealth.

This paper deals with decisions affecting household wealth accumulation. The abilities required to make more successful investment choices are not trivial as it requires knowledge of alternative rates of return and risks across different time horizons inherent in a complex variety of assets combined with family specific needs and goals about when these funds might be required. These investment decisions may well be among the most cognitively demanding that a family has to make.

It is reasonable then that cognitive skills may be potentially important determinants of family-level wealth accumulation decisions, especially in light of the enormous variation in holdings of financial assets and the relative risk in chosen asset portfolios. This variation has proven difficult to explain by conventional demographic factors, the amount of bequests received or that one anticipates giving (Smith, 1999), and the level of economic resources of the household.

It is not yet well established which aspects of cognition are most important, even at the highest conceptual level of differentiation made by cognitive psychologists between fluid intelligence (the ability to think clearly and quickly about a problem) or crystallized intelligence (the accumulated relevant knowledge about problems). These decisions may draw on cognitive skills related to memory retrieval, numeracy, retrieval fluency, and intact mental status. The value of these cognitive skills in economic decision making is especially important at older ages as individuals are increasingly asked to take greater control of or to 
adjust prior decisions relating to their household wealth, their pensions, and their health care.

There is very little prior research on who makes these financial decisions for the household and how that selection is influenced by their personal attributes and the relative cognitive abilities of both wives and husbands. In addition to this question of who makes these financial decisions and why, this research will examine the relationship between observed wealth outcomes of the household and these cognitive abilities of both spouses.

Our analysis will rely on data from selective waves of the Health and Retirement Survey (HRS), a nationally representative survey of Americans who are at least 50 years old. HRS is well known for its high quality measurement of many key SES outcomes; including income and wealth (Juster and Smith, 1997). In addition, HRS includes several salient dimensions of cognitive skills in the family, including (1) immediate and delayed memory recall, (2) the TICS battery which psychometrically captures episodic memory and intact mental status (McArdle et al., 2007), and (3) numeracy, a simple summary measure of respondents' numerical ability. A unique aspect of HRS is that these cognition constructs are self-reported by both spouses, which allows us to study the relationship between household wealth and the cognitive status of both spouses. ${ }^{1}$

This paper is divided into five sections. The next section describes the main data that we will use as well as the cognition variables available in the HRS for this analysis. Section 3 summarizes results obtained for joint spousal cognitive variables on the financial outcomes of the household. The fourth section includes models of who within the family becomes the main financial decision maker. The final section highlights our main conclusions.

\section{Cognition and Economics}

Whatever the origin of adult cognitive skills, financial matters are not straightforward for most individuals and may depend in part on their ability to invoke several dimensions of their cognitive skills. One may need to be interested in economic problems and feel comfortable in understanding the choices that are available amidst a wide array of options and then feel confident about the computations involved in contrasting alterative rates of return of different assets often calculated over different time horizons (Banks and Oldfield, 2007; Banks et al., 2009). This may involve aspects of (a) retrieving relevant prior financial information from memory, (b) using one's accumulated knowledge and skills (Crystallized intelligence $(\mathrm{Gc})$ ), and (c) the ability to draw inferences about what is the best solution to a novel problem (Fluid intelligence (Gf)) (for details, see Cattell, 1987; McArdle and Woodcock, 1998).

A useful shorthand division of the principal dimensions of intelligence is to separate them into fluid intelligence (Gf) and crystallized intelligence (Gc). Fluid intelligence is the thinking part—-memory, abstract reasoning, and executive function. In contrast, crystallized intelligence is the knowing part-the main accumulation of influence from education and lifetime experience (for more details, see McArdle et al., 2002).

In an insightful application, Delevande et al. (2008) consider an individual's knowledge of finance to be a component of human capital—or crystallized intelligence—-that allows people to achieve a higher expected return on their assets, holding risk constant. They

\footnotetext{
${ }^{1}$ HRS also collects cognitive information for about $8 \%$ of the HRS sample on numerical reasoning and retrieval fluency. However, this information is largely only collected for one of the two spouses so it is not useful in the context of this paper. In addition, McArdle et al. (2009) in an analysis of individual cognition attributes and wealth show that these dimensions of cognition are not that central at the individual level.
} 
assume that an individual produces additional financial knowledge by combining his or her fluid intelligence or ability, crystallized intelligence, and effort according to a human capital production function (Ben-Porath, 1967).

Other things equal, the value of acquiring financial knowledge is higher for persons who desire higher levels of retirement wealth because of a higher lifetime income, a lower rate of time preference or lower defined benefit pension wealth. Similarly, investment will be greater among persons who have lower costs or greater efficiency in acquiring additional knowledge because of greater fluid intelligence or because they have more financial knowledge obtained in their formal education or on-the-job.

These issues may become increasingly salient as the population ages because many aspects of these basic cognitive skills are known to begin to deteriorate from different levels and at varying rates for individuals starting in middle age and often at even earlier ages. As in other forms of human capital, crystallized intelligence is believed by cognitive psychologists to grow rapidly with age, but at a decreasing rate plateauing somewhere in the age 50 age range. In contrast, elements of fluid intelligence are thought to peak relatively early in life (during adolescence) and then steadily decline with age thereafter.

Problems associated with declines in fluid intelligence with age may be compounded if older individuals are asked to take more personal control of their accounts and the financial decisions about their wealth holdings and its future trajectory. To illustrate, Jappelli (2009) demonstrates that inhabitants of countries with more generous social security systems are generally less literate, lending support to the hypothesis that the incentives to acquire economic literacy are related to the amount of resources available for private accumulation.

\section{Data and Measures of Cognition in the Health and Retirement Survey}

This research will rely on the Health and Retirement Study (HRS), a nationally representative longitudinal survey of the population of the United States who are over 50 years old. The overall objective of the HRS is to monitor economic transitions in work, income, and wealth, as well as changes in many dimensions of health status among those over 50 years old. The current version of HRS is representative of all birth cohorts born in 1947 or earlier. Follow-ups of all surveys have taken place at approximately two-year intervals.

In HRS, questions were included in each core interview on demographics, income and wealth, family structure, health, and employment. An important advantage of these surveys is that they all contain high-quality wealth modules (Juster and Smith, 1997). In HRS, a very comprehensive and detailed set of questions was asked to measure household wealth. In addition to housing equity, assets were separated into the following ten categories: other real estate; vehicles; business equity; IRA or Keogh; stocks or mutual funds; checking, savings, or money market funds; CD's, government savings bonds, or treasury bills; other bonds; other assets; and other debt.

The subsets of HRS that we used are dictated by the types and availability of cognition measures in HRS (see Herzog and Wallace, 1997; Ofstedal et al., 2005). HRS cognition variables in HRS were intended to measure episodic memory, intactness of mental status, numerical reasoning, broad numeracy, and vocabulary.

We rely on two memory measures—immediate and delayed word recall—which are available in HRS in every wave in the same form since 1995. Respondents are read a list of ten simple nouns and are then asked first to immediately repeat as many of these words as they can in any order. After a five minute measurement of self-rated depression, they are 
then asked to recall as many of the original words as possible. ${ }^{2}$ Following recommendations in the analysis of McArdle et al. (2007), we form an episodic memory measure as the average of immediate and delayed recalled results. Episodic memory may be a necessary component of reasoning (which reflects both fluid and crystallized intelligence).

Our second cognitive measure is the mental status questions of the Telephone Interview of Cognitive Status (TICS) battery established to capture intactness or mental status of individuals. TICS questions consist of the following items - serial 7 subtraction from 100 (up to five times), backwards counting (from 20 to 1), naming today's date (month, day, year), and naming the President and Vice-President of the United States. Answers to these questions are aggregated into a single mental status score that ranges from 0 to 10 . At a most basic level, the need for an intact neuro-cognitive system is thought to be necessary to deal with everyday issues in communication and learning.

Starting with HRS 2002 and then asked in alternative waves for repeat interviews, three questions were added to the core interview to measure numeracy (respondents' numerical ability). These questions involve computation of three mathematical computations, and one is scored as either correct or incorrect on each of them. ${ }^{3}$ Four scores are possible running from zero to three depending on the number of correct answers. As pointed out by Banks and Oldfield (2007), there are several credible reasons why numeracy, a score representing knowledge about numerical problems, may be related to financial outcomes. More numerate individuals may be more adept at complex decision making including those involved in financial decisions (Peters et al., 2006). More numerate individuals also appear to be more patient, and are thus more likely to have saved and invested in the past (Parker and Fischhoff, 2005) and perhaps less risk averse (Benjamin et al., 2006).4

Thus there are three different measures of cognition available in the HRS that we use in this analysis-episodic memory, mental status, and numeracy. ${ }^{5}$ This form of availability determines the types of analysis that are possible. A very simple schematic of the translation of these HRS cognition measures into the Gf and Gc components of intelligence is as follows. Episodic memory is a very general measure of an important aspect of fluid intelligence since access to memory is basic to any type of cognitive ability. Most of the HRS variation in this measure is picking out the low end-people with bad memory. Numeracy, the actual ability to perform numerical skills mostly learned in schools, represents our preferred measure of Gc for numbers. Finally, the TICS score contains elements of both Gf and Gc-cognitive skills needed for everything but specific to nothing. The types of questions asked are not specific to the financial domains of life.

\footnotetext{
2In HRS 92 and 94, the original set consisted of 20 words. The same word list is not repeated in the next three subsequent rounds, and husbands and wives were given a different list (see Ofstedal et al. 2005).

${ }^{3}$ Another cognition measure is only available for the original cohort of HRS (those 51-61 years old in 1992) and was a one time measure. In HRS 92, a modified version of the Similarities subscale of the Wechsler Adult Intelligence Scale revised (WAIS-R) was used to access higher-level abstract reasoning by comparing a list of seven pairs of words and then describing how they were alike. ${ }_{5}^{4}$ Reverse causality is possible where greater involvement in complex financial decisions improves numerical ability.

${ }^{5}$ Two other cognitive measures are available in experimental modules in the HRS - the number series (a set of numerically related problems) and retrieval fluency. Since retrieval fluency measures the number of animals one can name in 45 seconds, it is not directly related to financial knowledge or ability. Since these experimental modules are given to only about 1,200 respondents selected randomly, the probability that both the husband and wife are both selected is very low. Fortunately, the analysis presented in McArdle, Smith, and Willis (2009) conducted at an individual level demonstrates that neither of these measures has any statistically significant relationship to household wealth. A more definitive assessment of these two dimensions of cognition, especially the more relevant number series, awaits placing them in the HRS core survey where they would be available for all respondents, including husbands and wives in the same family.
} 


\section{Spousal Level Analysis in the HRS}

A central analytical advantage of HRS is that interviews are conducted with both spouses and/or partners in the household. Thus, information is provided separately by both parties on dimensions of their own cognition and own personal attributes alongside the common household data on their wealth holdings and income. This allows an examination of the extent to which cognitive attributes of both spouses predict household wealth holdings and their composition, and whether cognition of one spouse is more important than the other at least for some of the key financial outcomes of the family. To conduct this research, a sample of married couples is used in the analysis throughout this paper.

To illustrate the nature of the joint relationship between financial outcomes and spousal cognition scores, Fig. 1 plots total household wealth against numeracy scores of the husband and wife. Household wealth increases sharply as either numeracy score rises, with large differences between those couples who each achieve a perfect score of three compared to those who collectively get the lowest possible score of zero correct answers. When both spouses answer all questions correctly, wealth is 1.7 million dollars-when neither spouse answers any question correctly, household wealth is about $\$ 200,000$.

Table 1 examines the relationship of numeracy scores of both spouses with total household wealth, total financial wealth, and the fraction of financial wealth held in stock. In this table, for reasons that will be apparent below, the data are arrayed by financial and non-financial respondents. Financial respondents are those selected by the household to answer all household-level financial variables including those measuring the amount, value, and composition of all financial assets. The financial respondent is supposed to the `most knowledgeable' person about the financial assets of the family and the chief financial decision maker.

All three wealth outcomes generally increase sharply with numerical scores of both financial and non-financial respondents. If both scores are zero (about $10 \%$ of cases), total wealth is about $\$ 200,000$. For families where both spouses get all numeracy questions correct, total household wealth is more than eight times higher- 1.7 million dollars. Wealth is generally higher when the numeracy scores of both financial and non-financial respondents are higher.

A similar but even more dramatic pattern exists for total financial wealth. For families where both spouses score three on the numeracy question, financial wealth is more than ten times larger than if both got all numeracy questions incorrect. There is a tendency for numeracy of the financial respondent to matter more since in four of the six off-diagonal pairs, financial wealth is larger if the higher numeracy score is that of the financial respondent. We will return to this issue below when discussing model estimates.

Our final measure is the fraction of financial assets held in stocks where one may think a priori that financial numeracy may matter even more given that the stakes are higher when rates of return are riskier. Once again there is evidence of sharp increases in the percent of the financial portfolio held in stocks as the numeracy score of each spouse rises. In this case of the fraction of financial assets held in stocks, in five of the six off-diagonals this fraction is larger when the financial respondent has a numeracy score higher than that of the nonfinancial respondent.

Thus, an important issue is whether finances are related symmetrically to cognitive ability of each spouse. In many households, especially in the HRS age range, there is almost complete specialization in financial decision making with one spouse in charge of most of the calls. In such a situation, the cognitive ability of the financial decision maker may matter more for household wealth outcomes. To investigate this possibility, we arrayed our cognitive 
measures in two different ways in Table 2-by gender and by the financially knowledgeable person (financial respondent) in the household.

Consider the stratification by gender or equivalently by husband and wife. TICS mental status is quite similar for men and women, levels of memory are higher for women, while numeracy is higher among men. When we shift instead to comparison between financial and non-financial respondents, financial respondents have the advantage in both intact mental status as well as numeracy, with little difference observed in the word recall measure.

The bottom panel of Table 2 simultaneously stratifies by gender and by whether one is a financial respondent. For women, there is little difference in cognitive scores between those who are and are not financial respondents. In contrast, for men financial respondents appear to have higher cognitive ability than male non-financial respondents in all three of our cognitive measures. One interpretation consistent with these data is that men are the default option for this component of financial decision making in the family unless their poor cognitive abilities get in the way.

Table 3 presents the correlation matrix of our cognitive variables for husbands and wives. There are two salient patterns. First, the correlation in scores within gender across cognitive measures is relatively low indicating - as supported by the cognitive psychological literature - that these three cognitive constructs are measuring different dimensions of cognition. Second, the correlation across husbands and wives is presumably mostly due to selective mating but also may reflect a common shared experience. This correlation between spousal cognitive measures is only 0.18 or word recall, rises to 0.23 for numeracy, and although it is much higher for intact mental status (0.504). Within person, episodic memory and numeracy are correlated ( 0.57 for husbands and 0.43 for wives). The correlations among these variables is not consistent with the pattern required by a single common factor (see Horn and McArdle, 2007) for either spouse, so the three cognitive variables will be treated as indicators of several cognitive functions. Another advantage of these relatively low correlations is that our analysis will not be plagued by excess multi-colinearity across these alternative cognitive measures. ${ }^{6}$

\subsection{Models of household wealth}

In this section, we report our empirical results describing the relation of dimensions of cognition of both spouses to wealth accumulation among middle-aged and older adults. We estimate separate models for three financial outcomes: total household wealth, total financial wealth, and the fraction of financial wealth held in stocks. These models are estimated over a sample of married couples

These models are estimated both in level form (in calendar year 2006) in Table 4 and as changes from a year 2000 base to year 2006 in Table 5. The estimated coefficients and associated ' $t$ ' statistics based on robust standard errors are listed in these Tables. Noncognition variables included in these models are standard: gender of the respondent $(1=$ female), race ( 1 = African-American), Hispanic ( 1 = Latino), a quadratic in age, a quadratic in average household income between 1998 and 2006, the percent of 2006 non-capital household income due to the husband, ${ }^{7}$ and the number of years of schooling completed. We take an average of household income from the 1998 to 2006 HRS waves in order to better approximate long-run average or permanent income of families. ${ }^{8}$

\footnotetext{
${ }^{6}$ Of course, these low correlations to some extent reflect non-shared measurement errors in these variables.

${ }^{7}$ We do not include capital income when constructing this variable since the amount of capital income is a consequence of the level of wealth.
} 
Education and age variables are included for financial and non-financial respondents. The only non-standard demographic variable is an indicator variable for whether the respondent was the financial respondent- the partner who was most knowledgeable about financial matters and who answered all household-level financial questions in the HRS survey. Missing value indicators are included in all models for people who either did not answer or who were not asked specific questions involved in the construction of the right hand side variables.

Table 4 presents results for estimates of relationship between cognitive attributes of both spouses and the three financial outcomes for the household. Results obtained in the 2006 level analysis for non-cognitive variables, presented in Table 4, are consistent with those widely reported in the literature (Smith, 1995). Wealth levels, both total and financial, tend to be lower for minorities, increase at a decreasing rate with age for both partners, and rise steeply with education and with average family income, but with the latter at a decreasing rate. Individuals with higher education, income, and wealth hold more of their financial wealth in stock while African-Americans hold less in more risky assets even at the same age, average income, and wealth.

Turn next to the estimates for the cognition variables. There is little evidence of any systematic relation for the TICS mental status measure for either spouse. ${ }^{9}$ With the exception of total wealth measure (where estimated effects are actually higher for nonfinancial respondents), word recall has similarly estimated impacts for both financial and non-financial respondents. The critical distinction relates to our numeracy measure where estimated effects for financial respondents are five times larger than numeracy of nonfinancial respondents. Higher numeracy is also related to a larger fraction of assets in stocks with a somewhat stronger relationship estimated for numeracy of the financial respondent. ${ }^{10}$ An increase in the fraction of family income contributed by the husband also increases the fraction of the portfolio held in stocks.

The results summarized thus far pertain to wealth levels and composition in calendar year 2006. The panel nature of HRS allows us to examine the association of these cognition measures with changes in wealth observed in the panel. Table 5 contains the couple-level analysis when the outcome is the change in wealth between 2000 and 2006. All right-hand side variables are the same as in the level analysis in Table 4, but a control is added for year 2000 total household wealth or financial wealth depending upon the financial outcome under investigation.

Not surprisingly, estimated effects of all non-cognitive variables are similar to those obtained from the 2006 level analysis, but are much smaller in magnitude since now we are predicting changes between the 2006 and 2000 HRS waves. For the two cognitive measures that really matter-word recall and especially numeracy—estimated impacts are larger when

\footnotetext{
${ }^{8}$ We average across the number of waves between 1998 and 2006 in which the family was in the HRS and put an indicator variable in these models for the number of years in which the averaging took place. The results we obtain for the cognition variables are very similar if we used 2006 family income instead.

${ }^{9}$ In the 2006 HRS the TICS battery of questions are only asked for those ages 65 and over because over $90 \%$ of respondents younger than 65 when they first entered the survey received a nine or ten in TICS. However, we obtain virtually the same results for the TICS score as well as all other cognition variables if we replaced the missing value for those less than 65 with the score they obtained when they first entered the survey. Alternatively, giving those under age 65 a TICS score of ten in the 2006 wave also produces the same set of estimates. We thank Alan Gustman for his suggestions on this point.

${ }^{10}$ Our paper deals with household wealth excluding social security and pensions. Compared to the other two forms of wealth, household wealth is by far the most active account. HRS only defines social security wealth and pension wealth on its public website for those who are pre-retirement or pre-receipt, a very different sample than that used in our analysis. In a recent paper, Gustman et al. (2010) used a sample of HRS respondents 51-56 years old and replicated our results using total wealth (including social security and pension wealth). The central results of our analysis - the primacy of numeracy in predicting wealth and the larger predictive effects for the financial respondent compared to the non-financial respondent-were maintained.
} 
it is a trait of the financial respondent. For total and financial wealth, the impact of numeracy is not even statistically significant for the non-financial respondent. For the portfolio analysis of the fraction in stock in the final column of Table 5, the numeracy score of the non-financial respondent is not statistically significant, while that of the financial respondent has a strong positive effect.

The extreme degree of heterogeneity and right skewness in financial outcomes implies that estimated mean effects may not characterize many individuals in the sample. With that in mind, Tables 6 and 7 presents quantile models (estimated at the $25^{\text {th }}, 50^{\text {th }}, 75^{\text {th }}$, and $90^{\text {th }}$ quantiles) for total household wealth and total financial wealth for our sample of couples. As expected, estimated effects of most of the non-cognitive variables increase as we move up towards higher quantiles in the total wealth and non-financial wealth distribution.

As before, we find increasing impacts of numeracy as we move to higher percentiles in the wealth distribution. This increase is even steeper for numeracy of the financial respondent implying that the much lower estimated impact of numeracy for the non-financial respondent is particularly the case at higher levels of wealth. This is even more so when we examine total household financial wealth as the economic outcome.

\section{Who is the Financial Respondent?}

These results in the previous section indicating both a strong association of education and dimensions of cognition with financial outcomes of the family, and the dominance of financial respondents' attributes raises an issue of how the family decides who shall be the financial respondent. HRS asks the family to reveal who is the most knowledgeable financial person - the husband or the wife — and that person answers all financial questions about family income and wealth holdings. It seems reasonable that the selected person had the major role in financial decision making for the family. What are the traits of both partners that influence this choice?

Table 8.A lists the percent of cases for married couples where the husband is selected as the financial respondent, stratified by age of both husbands and wives. In $62 \%$ of households, men are the financial respondent indicating a strong tilt towards men at least in these birth cohorts. This male preference is particularly pronounced when the husband is much older than his wife. To illustrate, in marriages with husbands in their seventies and with wives who are at least ten years younger, in $82 \%$ of the cases men are financial respondents. Especially when wives are young, the selection of males as financial respondents increases sharply as men are older. Conditional, on husbands' age, the probability of selecting women as the financial respondent increases with wives' age, but the wife's age gradients are not as dramatic as that of her husband.

Table 8.B arrays the same data but now stratified by education of both spouses. Increases in education of either spouse raise the probability of being selected as the financial respondent. Education is more sharply graded than age, and husbands' education apparently has a larger impact than that of his spouse. If the husband is a college graduate, the odds are more than three to one that he will be the financial respondent no matter what the education of the wife is.

Table 8.C stratifies the data by the numeracy scores of the husband and wife. Of all three attributes used in this series labeled Table 8 , by far the selection of the husband as the financial respondent is most sensitive to this husband's attribute and least sensitive to the wife's attribute. Even when the husband scored a perfect zero on his numeracy test, it is basically $50-50$ that he would be selected as the financial respondent, a result that is only slightly altered by his wife's numeracy score. In sharp contrast, when the husband answered 
all the numeracy questions correctly with a perfect score of three, he is the financial respondent in $80 \%$ of the cases, once again a result that is only slightly affected by his wife's score.

Table 8.D highlights the tendency for a family to select as the financial decision maker the partner with the higher numeracy score. The sample for this table is those couples whose numeracy scores are not the same. For each combination of non-equal numeracy scores, Table 8.D lists the percent of cases in which the partner selected as the financial respondent is the one with the higher numeracy score. In two-thirds of all cases of non-identical numeracy scores, the spouse with the higher of the two scores is the financial respondent. Moreover, that tendency appears to increase the further apart the two numeracy scores are. For example, compare the two numeracy score combinations ( 0 and 1$)$ and ( 0 and 3$)$. In the first case, the higher-scored partner is selected $66 \%$ of the time, while in the second case the spouse with the higher numeracy score is the financial respondent in $82 \%$ of the cases.

Table 9 presents a multivariate model where the outcome is one if men are the financial respondent and zero otherwise. Once again, the two variables measured at the household level are a quadratic in average household income for all HRS rounds in the survey between 1998 and 2006, and the fraction of 2006 non-capital family income that is attributed to the husband. All other variables are individual attributes of husbands and wives and include a set of age dummies, years of education, and the three cognition variables. Since the complement of men being the financial respondent is that women perform those duties, the effects of all variables for women being the financial respondent are exactly the same with a reversal of sign. The final column in Table 9 provides a statistical $\mathrm{F}$ test for whether the absolute value of the coefficients of wives' and husbands' attributes is the same for all individual-level variables.

Total average family income between the 1998 and 2006 waves has a non-linear effect on the probability that the male is the financial respondent, with that probability initially rising and then falling as average family income increases. The fraction of current family income that is attributed to the husband strongly predicts that the husband is more likely to be the financial respondent. Apparently, as a spouse accounts for a larger fraction of family income, it becomes more likely that this spouse will be in charge of family finances. Age coefficients (with 80+ as the omitted class) suggest even more strongly than the cross-tabs in Table 8 did that the presence of emerging cohort effects are loosening male preference in these financial decisions. This may be even more so for cohorts younger than those represented in the HRS sample which starts basically at age 50. Effects of education and all three cognitive variables are statistically significant for both spouses, but are always quantitatively larger for husbands than they are for wives. While all cognition and education variables and the differences in size of impact between wives and husbands are statistically significant, impacts of numeracy are particularly strong for both marriage partners. In general, the estimated impact of wives' cognition variables are about half that of their husbands.

The data contained in Table 10 suggest that choosing the wrong person as the financial respondent may have consequences. In this Table, we compare levels of total household wealth, total household financial wealth, and the percent of financial assets in stocks in families where the financial respondent's core is greater than, equal to, or less than that of the non-financial respondent. The final column lists the percent of families in each one of these comparisons. We make these comparisons for education and the two cognitive variables that appear to matter-numeracy and verbal recall. 
Families choose the less-numerate spouse in less than a fifth of the cases, but when that choice happens total household wealth and total financial wealth is less than it is when the spouses are equal in numeracy or the financial respondent has a higher numerical score. A similar pattern is found with education as wealth levels are lowest and less risky if the lesseducated spouse is the financial respondent. No such pattern of differential wealth outcomes exist when we turn to memory recall.

\section{Conclusions}

Inclusion of individual cognitive measures in prediction of economic outcomes has turned out to be useful. Numeracy, as measured by answers to three simple mathematical questions, is by far the most predictive of wealth among all cognitive variables in the HRS sample. This is thought by cognitive psychologists to be a direct measure of a specific and practical form of numerical knowledge (i.e., a form of Crystallized Intelligence). We found independent impacts which were statistically significant for all three financial outcomes and for financial and non-financial respondents alike. Perhaps more importantly, the estimated impact of answering a question correctly is much higher for the financial respondent compared to non-financial respondents in all three outcomes. To illustrate, the estimated effect of answering a question correctly is $\$ 22,000$ greater household wealth for the financial respondent and only $\$ 4,000$ if one is the non-financial respondent. Episodic memory (or word recall) also appears to be related to the total and financial wealth holdings of the family, and in this case it applies to both the financial and non-financial respondent.

The type of unabashedly exploratory and descriptive analysis in this paper cannot establish causal pathways for these associations. There is no randomization in the cognitive ability of HRS respondents, and one can easily think of correlates of these cognitive measures that may offer plausible alternative reasons for these associations. For example, Van den Berg et al. (2009) show that the later-life cognitive abilities of individuals born during a recession suffer more strongly from a stroke than the cognitive abilities of individuals born in years with a favorable business cycle. Nor should it be easily dismissed that a history of lifetime interests in financial matters and investments in the stock market, for example, could lead to improved numerical ability. Separating out the dual plausible pathways should be a high research priority.

Yet, the presence of these estimated effects of numeracy on total and financial wealth at lower wealth quartiles where levels of commitment of investors is relatively modest should caution at least against a purely reverse pathway from investments to cognitive ability. For some cognitive functions, such as numerical ability, the cognitive training of these skills seems to be readily attainable by most persons, and the economic returns seem high. At a minimum, the type of strong associations in descriptive analysis in this paper is a signal that one may want to pursue studies that may offer more discriminating tests of whether these associations can be thought of as plausibly causal.

\section{Acknowledgments}

We would like to thank Iva MacLennan and David Rumpel for excellent programming assistance. This research was supported by grants (AG025529 and AG008291) from the National Institute of Aging to the RAND Corporation, to the University of Southern California (AG07137) and to the University of Michigan (AG026571).

\section{References}

Becker, GS. A Treatise on the Family. Harvard University Press; Cambridge, MA: 1991.

Banks J, Oldfield Z. Understanding pensions: cognitive function, numerical ability and retirement saving. Fiscal Studies. 2007; 28(2):143-70.

Econ J (London). Author manuscript; available in PMC 2011 November 1. 
Banks, J.; O'Dea, C.; Oldfield, Z. Cognitive function, numeracy and retirement saving trajectories. 2009. unpublished paper

Benjamin, DJ.; Brown, SA.; Shapiro, JM. Who is "behavioural"? Cognitive ability and anomalous preferences. 2006. http://ssrn.com/

Ben-Porath Y. The production of human capital and the life cycle of earnings. The Journal of Political Economy. 1967; 75(4):352-65. part 1.

Cattell, RB. Intelligence: Its Structure, Growth, and Action. Elsevier Science; New York: 1987.

Delevande, A.; Rohwedder, S.; Willis, RJ. Michigan Retirement Research Center Working Paper. 2008. Preparation for retirement, financial literacy and cognitive resources; p. 2008-190.

Gustman, AL.; Steinmeier, T.; Tabatabai, N. Financial knowledge and financial literacy at the household level. 2010. unpublished paper

Herzog AR, Wallace RB. Measures of cognitive functioning in the AHEAD study. Journals of Gerontology Series B, Psychological and Social Sciences. 1997; 52:37-48.

Horn, JL.; McArdle, JJ. Understanding human intelligence since Spearman. In: Cudeck, R.; MacCallum, R., editors. Factor Analysis at 100 Years. Lawrence Erlbaum Associates, Inc.; Mahwah, NJ: 2007. p. 205-47.

Jappelli, T. Centre for Studies in Economics and Finance (CSEF) Working Paper No. 238. University of Naples; Italy: 2009. Economic literacy: an international comparison.

Juster FT, Smith JP. Improving the quality of economic data: lessons from HRS and AHEAD. Journal of the American Statistical Association. 1997; 92(440):1268-78.

McArdle JJ, Ferrer-Caja E, Hamagami F, Woodcock RW. Comparative longitudinal structural analyses of the growth and decline of multiple intellectual abilities over the life span. Developmental Psychology. 2002; 38(1):115-42. [PubMed: 11806695]

McArdle JJ, Fisher GG, Kadlec KM. Latent variable analysis of age trends in tests of cognitive ability in the Health and Retirement Survey, 1992-2004. Psychology and Aging. 2007; 22(3):525-545. [PubMed: 17874952]

McArdle, JJ.; Woodcock, RW., editors. Human Abilities in Theory and Practice. Lawrence Erlbaum Associates; Mahwah, NJ: 1998.

McArdle, JJ.; Smith, JP.; Willis, R. New Directions in the Economics of Aging. University of Chicago Press; Chicago: 2011. Cognition and economic outcomes in the Health and Retirement Survey.

Ofstedal, M.; Beth Fisher, GG.; Herzog, AR. HRS Documentation Report DR-006. 2005. Documentation of cognitive functioning measures in the Health and Retirement Study.

Parker AM, Fischhoff B. Decision-making competence: external validation through an individualdifferences approach. Journal of Behavioral Decision Making. 2005; 18:1-27.

Peters E, Västfjäll D, Slovic P, Mertz CK, Mazzocco K, Dickert S. Numeracy and decision making. Psychological Science. 2006; 17(5):407-13. [PubMed: 16683928]

Smith JP. Racial and ethnic differences in wealth in the Health and Retirement Study. Journal of Human Resources. 1995; 30:S158-83.

Smith, JP. Inheritances and bequests. In: Smith, JP.; Willis, R., editors. Wealth, Work, and Health: Innovations in Measurement in the Social Sciences. University of Michigan Press; Ann Arbor, MI: 1999. p. 121-49.

Van den Berg, GJ.; Deeg, D.; Lindeboom, M.; Portrait, F. IZA Discussion Paper No. 4780. 2010. The role of early-life conditions in the cognitive decline due to adverse events later in life. 


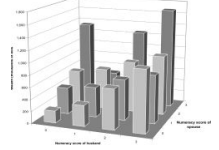

Fig. 1.

Wealth by Numeracy Score of Husband and Wife 
Table 1

Total Wealth by Numeracy of Spouse (wealth in thousands of dollars)

Total Wealth

\begin{tabular}{crrrrr}
\hline & \multicolumn{5}{c}{ Numeracy Score of Non-Financial Respondent } \\
Numeracy Score of Financial Respondent & $\mathbf{0}$ & $\mathbf{1}$ & $\mathbf{2}$ & $\mathbf{3}$ \\
\hline 0 & 202.3 & 339.8 & 548.5 & NA \\
1 & 388.4 & 505.1 & 615.7 & 564.9 \\
2 & 684.5 & 685.8 & 852.6 & $1,357.5$ \\
3 & 971.5 & 818.3 & 953.8 & $1,679.4$ \\
\hline
\end{tabular}

Total Financial Wealth

Numeracy Score of Spouse of Non-Financial Respondent

\begin{tabular}{crrrr} 
Numeracy Score of Financial Respondent & $\mathbf{0}$ & $\mathbf{1}$ & $\mathbf{2}$ & $\mathbf{3}$ \\
\hline 0 & 94.7 & 184.1 & 283.0 & NA \\
1 & 232.9 & 331.8 & 393.8 & 317.6 \\
2 & 466.7 & 445.7 & 545.3 & 888.5 \\
3 & 620.0 & 536.8 & 651.0 & $1,066.0$ \\
\hline
\end{tabular}

Fraction of Financial Wealth in Stocks

\begin{tabular}{ccccrr}
\hline & \multicolumn{4}{c}{ Numeracy Score of Spouse of Non-Financial Respondent } \\
Numeracy Score of Financial Respondent & $\mathbf{0}$ & $\mathbf{1}$ & $\mathbf{2}$ & $\mathbf{3}$ \\
\hline 0 & 3.0 & 6.3 & 9.4 & NA \\
1 & 6.1 & 9.0 & 11.1 & 11.6 \\
2 & 9.8 & 11.7 & 13.5 & 15.9 \\
3 & 11.4 & 18.1 & 17.1 & 17.5 \\
\hline
\end{tabular}

NA—number of observations is less than 50. 
Table 2

Means of Cognition Variables by Gender and Whether Financial Respondent (sample of married couples)

\begin{tabular}{lcccc}
\hline & Male & Female & Financial Respondent & Non-Financial Respondent \\
\hline TICS Mental Status (0-10) & 8.958 & 8.924 & 9.125 & 8.735 \\
Word Recall (0-10) & 4.704 & 5.377 & 5.086 & 5.016 \\
Numeracy (0-3) & 1.464 & 1.169 & 1.450 & 1.165 \\
\hline
\end{tabular}

\begin{tabular}{lcccc}
\hline & Male Financial Respondent & Male Non-Financial Respondent & Female Financial Respondent & Female Non-Financial Respondent \\
\hline $\begin{array}{l}\text { TICS Mental Status } \\
(0-10)\end{array}$ & 9.203 & 8.505 & 8.974 & 8.893 \\
Word Recall (0-10) & 4.883 & 4.378 & 5.399 & 5.362 \\
Numeracy (0-3) & 1.606 & 1.205 & 1.209 & 1.143 \\
\hline Note. HRS 2006-62\% of financial respondents are men.
\end{tabular}




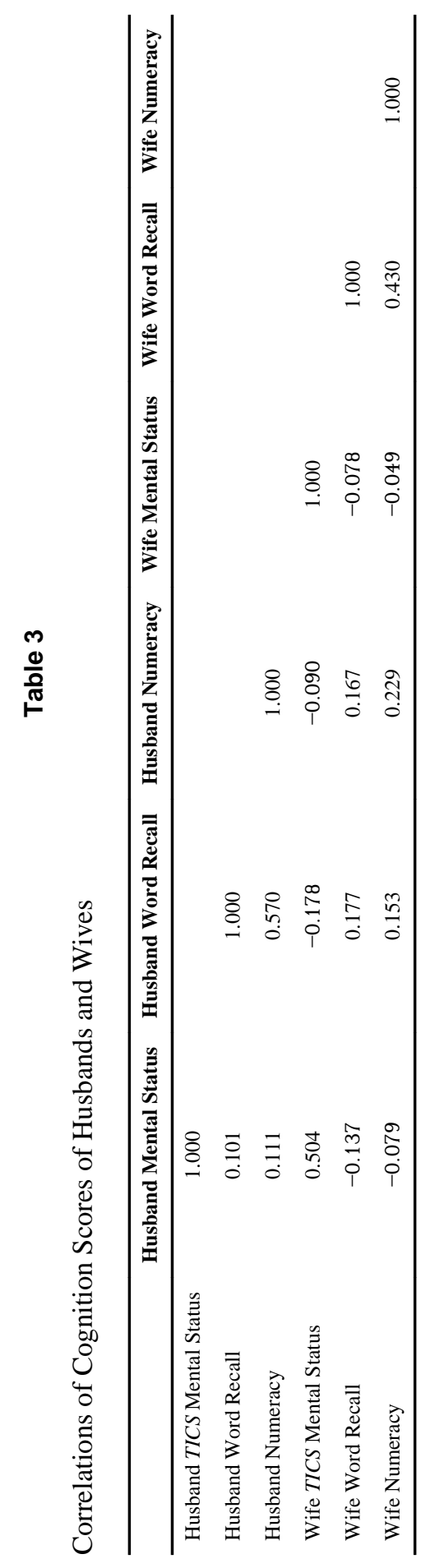

Econ J (London). Author manuscript; available in PMC 2011 November 1. 


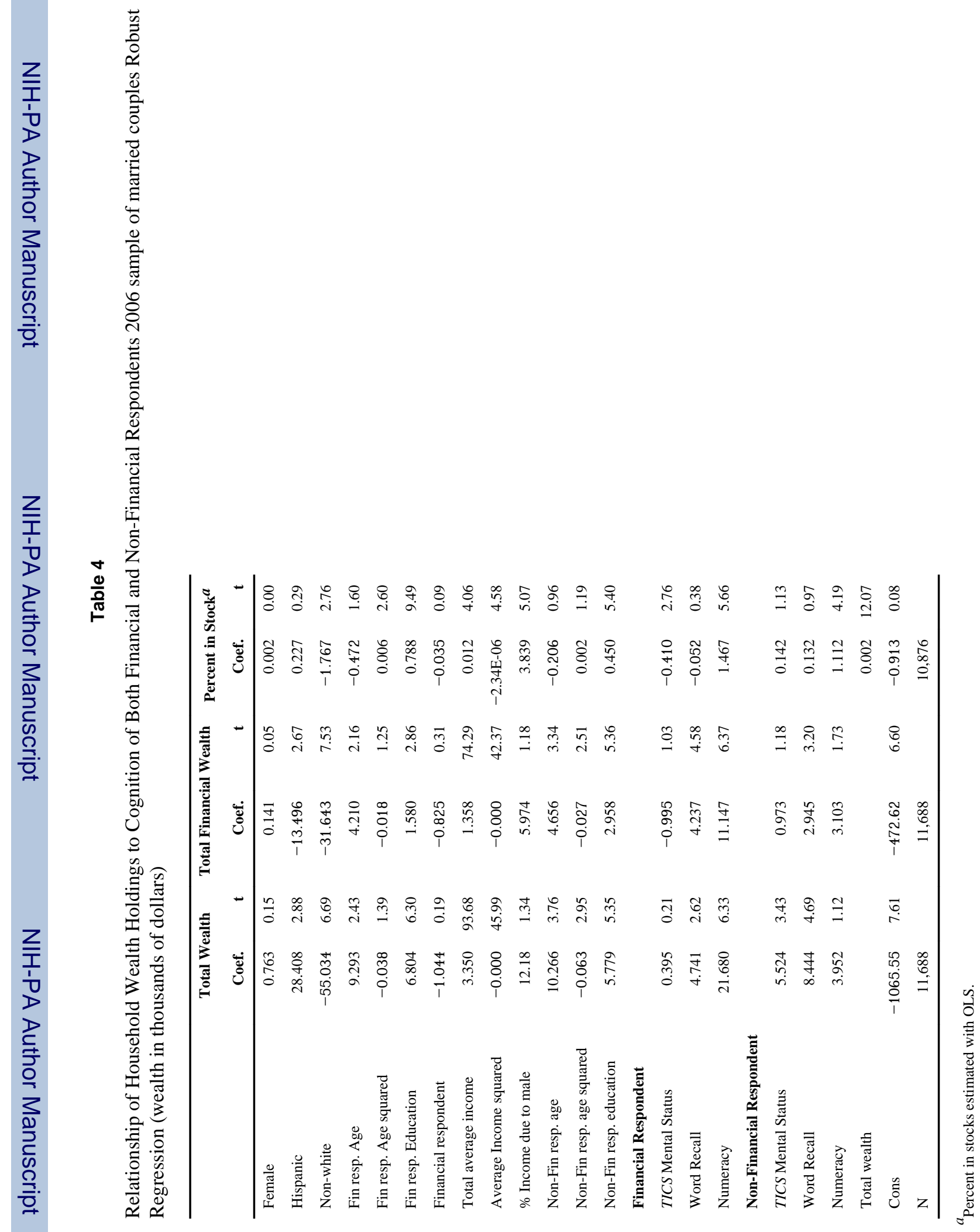




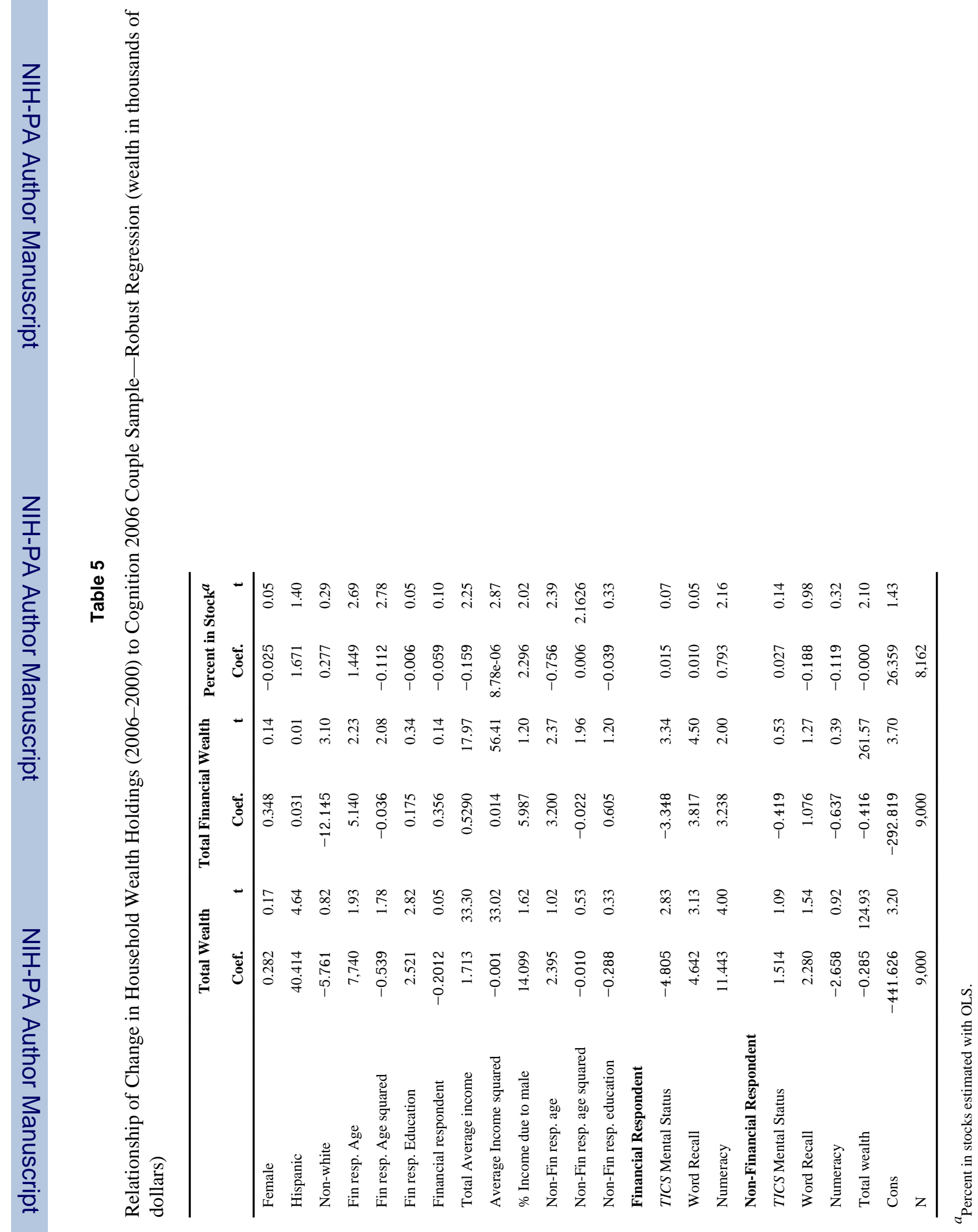




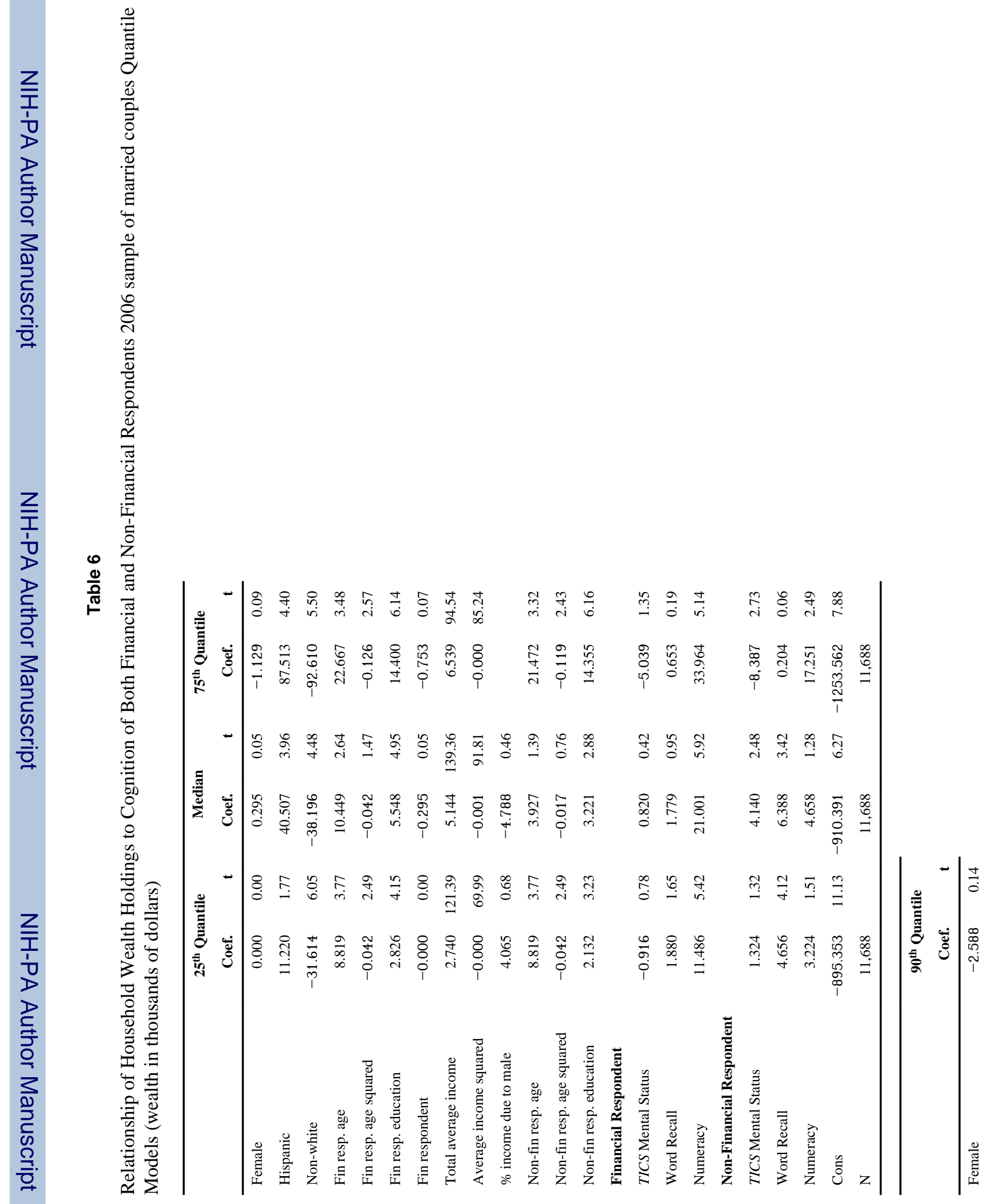




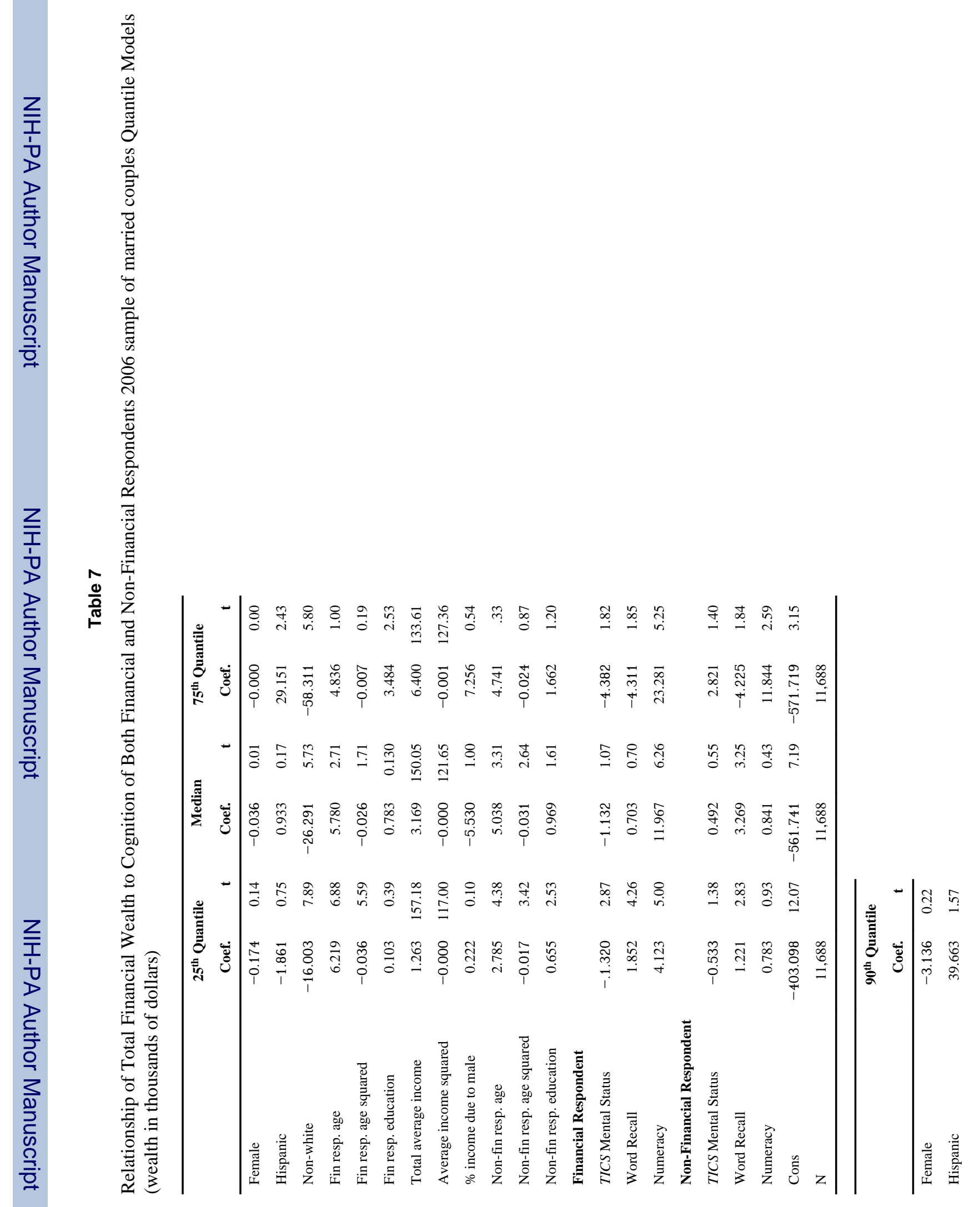




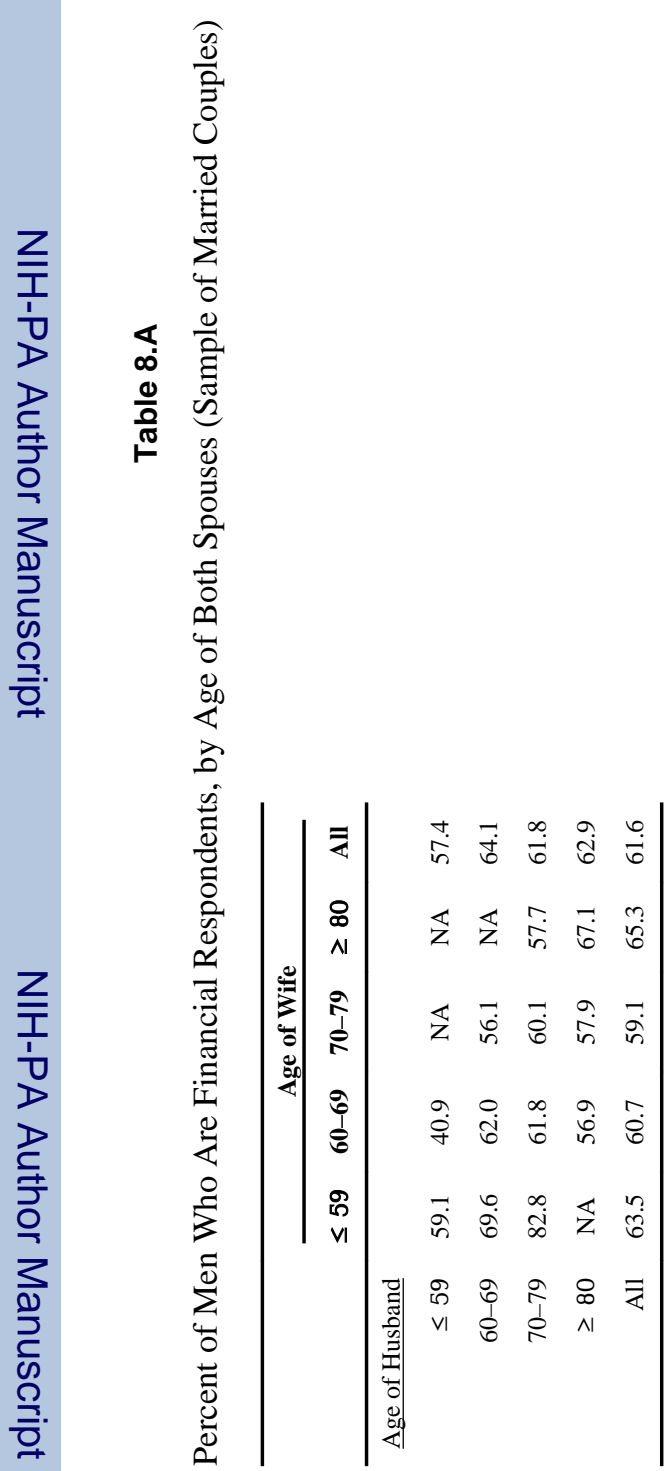




\section{Table 8.B}

Percent of Men Who Are Financial Respondents, by Education of Both Spouses

\begin{tabular}{lcccc}
\hline & \multicolumn{4}{c}{ Education of Wife } \\
\cline { 2 - 5 } & $<$ HSG & HSG & College or More & All \\
\hline Education of Husband & & & & \\
< High School & 55.4 & 44.7 & 38.5 & 49.9 \\
High School & 68.5 & 58.3 & 55.6 & 59.6 \\
College Grad & 88.2 & 75.6 & 75.4 & 75.9 \\
All & 61.1 & 59.5 & 67.6 & 61.6 \\
\hline
\end{tabular}

Econ J (London). Author manuscript; available in PMC 2011 November 1. 


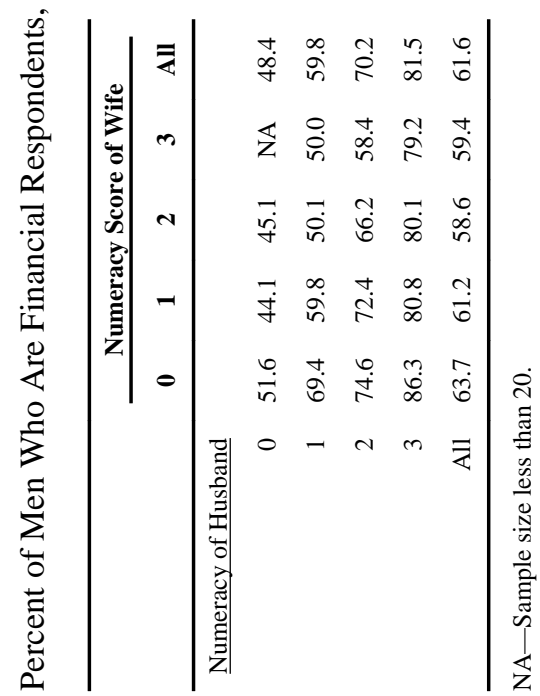

Econ J (London). Author manuscript; available in PMC 2011 November 1. 


\section{Table 8.D}

Percent of Cases with Non-Equal Numeracy Scores where Higher Score Is that of Financial Respondent

\begin{tabular}{cc}
\hline Numeracy Score Combination & \\
$0-1$ & $66.1 \%$ \\
$0-2$ & $70.7 \%$ \\
$0-3$ & $82.3 \%$ \\
$1-2$ & $63.6 \%$ \\
$1-3$ & $75.4 \%$ \\
$2-3$ & $68.0 \%$ \\
All non-equal scores & $67.6 \%$ \\
\hline
\end{tabular}


Table 9

OLS Predicting If Male Is Financial Respondent (Sample of Married Couples)

\begin{tabular}{|c|c|c|c|}
\hline & Coef. & $\mathbf{t}$ & "F test" for Difference Between Male and Female Coefficient \\
\hline Total income & 0.0002 & 2.63 & \\
\hline Income squared & $-2.54 \mathrm{e}-08$ & 1.64 & \\
\hline$\%$ income due to male & 0.2040 & 8.72 & \\
\hline \multicolumn{4}{|l|}{$\underline{\text { Husband }}$} \\
\hline Age $<59$ & -0.0974 & 2.55 & \\
\hline Age 60-69 & -0.0734 & 2.50 & \\
\hline Age $70-79$ & -0.0414 & 1.66 & \\
\hline Education & 0.0189 & 8.05 & \\
\hline TICS mental status & 0.0155 & 3.80 & \\
\hline Word recall & 0.0235 & 5.20 & \\
\hline Numeracy & 0.0742 & 9.54 & \\
\hline \multicolumn{4}{|l|}{$\underline{\text { Wife }}$} \\
\hline Age $<59$ & 0.1894 & 4.96 & 5.35 \\
\hline Age 60-69 & 0.0299 & 0.90 & 2.33 \\
\hline Age $70-79$ & -0.0330 & 1.11 & 7.22 \\
\hline Education & -0.0084 & 3.17 & 14.69 \\
\hline TICS mental status & -0.0001 & 0.02 & 15.62 \\
\hline Word recall & -0.0127 & 3.10 & 3.38 \\
\hline Numeracy & -0.0569 & 7.04 & 2.50 \\
\hline
\end{tabular}


Table 10

Wealth Outcomes by Comparison of Financial Scores of Financial and Non-Financial Respondents (Men are the Financial Respondent)

\begin{tabular}{ccccc}
\hline Comparison & Wealth $^{\boldsymbol{a}}$ & Financial Wealth $^{\boldsymbol{a}}$ & \% in stocks & \% of cases \\
\hline Numeracy & & & & \\
Fin < NFin & 632 & 400 & 10.1 & 17.0 \\
Fin = NFin & 722 & 469 & 10.6 & 34.7 \\
Fin > NFin & 713 & 463 & 11.7 & 48.3 \\
Education & & & & \\
Fin < NFin & 589 & 356 & 8.0 & 28.0 \\
Fin $=$ NFin & 742 & 480 & 11.8 & 28.1 \\
Fin > NFin & 749 & 498 & 12.0 & 44.0 \\
Verbal recall & & & & \\
Fin < NFin & 724 & 473 & 11.7 & 54.4 \\
Fin $=$ NFin & 660 & 448 & 10.3 & 9.7 \\
Fin > NFin & 681 & 427 & 10.2 & 35.9 \\
\hline$a_{\text {In thousands of dollars. }}$ & & &
\end{tabular}

Econ J (London). Author manuscript; available in PMC 2011 November 1. 